\title{
Histopathological features of antrochoanal polyps in Chinese patients*
}

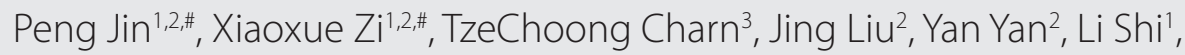 \\ Hailing Zhang ${ }^{1 \dagger}$, Deyun Wang ${ }^{2 \dagger}$ \\ Rhinology 56: 4, 378-385, 2018 \\ https://doi.org/10.4193/Rhin18.057 \\ 'Department of Otolaryngology, The Second Affiliated Hospital, Shandong University, Jinan, China \\ *Received for publication: \\ 2 Department of Otolaryngology, National University of Singapore, National University Health System, Singapore, Singapore \\ March 15, 2018 \\ ${ }^{3}$ Departments of Otolaryngology, Sengkang General Hospital and Singapore General Hospital, Singapore, Singapore \\ Accepted: May 11, 2018 \\ \#, Contirbuted equally
}

Background: The pathogenesis and etiology of antrochoanal polyps (ACP) are unclear. The aim of this study is to characterize the features of inflammatory cellular infiltration, the epithelial remodeling patterns and their associations to clinical parameters in ACP.

Methods: A detailed histological study employing classic immunohistochemistry was performed. 33 ACPs, 49 classic bilateral nasal polyps (BNP) and 50 controls were obtained. The histological patterns and inflammatory cells infiltration were evaluated and analyzed for associations with clinical characteristics.

Results: Less severe epithelial hyperplasia and goblet cell hyperplasia were found in ACP compared to BNP. In ACP, 87.9\% of cases demonstrated neutrophilia. Elevated proportions of macrophages and CD8 ${ }^{+} T$ cells, and elevated infiltration of mast cells was observed. Eosinophil infiltration was found to be positively corelated with a history of asthma; macrophages proportion was analyzed to have a significantly negative correlation with epithelial hyperplasia and goblet cell hyperplasia; the infiltration of CD8 ${ }^{+}$ T cell and squamous metaplasia were found to have a positive correlation.

Conclusion: Inflammation potentially has important roles in ACP. ACP may differ in its pathogenesis from classic bilateral nasal polyps.

Key words: antrochoanal polyps, clinical characteristics, epithelial remodeling, inflammatory cells, Chinese ethnicity

\section{Introduction}

The antrochoanal polyp (ACP) is a common benign sinonasal condition. It is defined as the maxillary sinus polyp originating from the maxillary sinus mucosa, passing through the ostium, and extending into the choana ${ }^{(1,2)}$. It comprises $4-6 \%$ of nasal polyps and epidemiologically it affects more children and young adults ${ }^{(3)}$. ACPs are invariably unilateral, and bilateral cases are extremely rare ${ }^{(1-4)}$. Considerable efforts have been made to research into the molecular and cellular basis of bilateral nasal polyps (BNP) during the last 2 decades. Conversely little is known about the pathogenesis and etiology of antrochoanal polyps. This may be because of its relatively low incident rate ${ }^{(1,5)}$.
Epithelial remodeling is an important feature of airway diseases, and epithelial hyperplasia, hyperplasia of goblet cells and squamous metaplasia are forms of abnormal epithelial remodeling ${ }^{(6,7)}$. Additionally, both the innate immune response and the adaptive immune system contribute to the chronic inflammation in patients with nasal polyps ${ }^{(8)}$. Epithelial remodeling has been well studied in the lower respiratory tract ${ }^{(9,10)}$ and some upper respiratory tract diseases such as bilateral nasal polyps ${ }^{(11)}$ and nasal inverted papilloma ${ }^{(12)}$, but not in antrochoanal polyps, regardless of ethnicity. Comprehensive inflammatory cell studies have been performed to understand the pathogenesis of nasal polyps ${ }^{(11,13)}$ and guide clinical therapies ${ }^{(14)}$, but such studies in ACP are lacking. 
In light of the paucity of ACP research, we conducted a comprehensive histological study of a relative large sample size of Chinese ACP, to determine the features of inflammatory cellular infiltration, the epithelial remodeling patterns, their associations with clinical parameters, and compare those with bilateral nasal polyps and controls.

\section{Materials and methods}

Patients and samples

Patients with biopsy-proven unilateral antrochoanal polyps ( $n=33$ ) and bilateral nasal polyps ( $n=49$ ), who subsequently underwent endoscopic nasal surgery, were recruited from the Department of Otolaryngology in the Second Affiliated Hospital of Shandong University, Shandong, China. Inferior turbinate (IT) biopsies were obtained from subjects $(n=50)$ with symptomatic nasal septal deviation requiring septoplasty surgery and served as controls. None of the controls had chronic rhinosinusitis with or without NP. Atopy was confirmed by either serum specific immunoglobulin E ( $\operatorname{lgE}$ ) test or skin prick test to common aero-allergens. Asthma was defined as self-reported physiciandiagnosed asthma. History of recurrence was obtained during history taking and confirmed by intraoperative endoscopic evidence of prior nasal surgery. Smokers are defined as current cigarette smokers who consume one or more packs of cigarettes a day, averaged over 1 year. Fresh specimens obtained were fixed in formalin and embedded in paraffin for histological evaluation. Approval for this study was obtained from the institutional review board (IRB) of the Second Affiliated Hospital of Shandong University, China.

Hematoxylin and eosin staining and immunohistochemical study

Biopsy samples (antrochoanal polyps, bilateral nasal polyps and controls) were fixed in formalin, embedded in paraffin and sectioned at $4 \mu \mathrm{m}$. Patterns of epithelial hyperplasia in biopsy specimens were evaluated based on hematoxylin and eosin (H\&E) stained slides. Immunohistochemistry of a rabbit antihuman MUC5AC polyclonal antibody (Santa Cruz, Dallas, TX, USA), a marker of goblet cell, was performed to confirm the presence of goblet cell hyperplasia. Immunohistochemistry of a mouse monoclonal anti-human Involucrin [Clone SY5](Abcam, Cambridge, United Kingdom), a marker of squamous metaplasia, was performed when the presence of squamous metaplasia was uncertain.

Eosinophils were highlighted by H\&E staining. Other inflammatory cell infiltration patterns were detected by immunohistochemical staining. The specific cellular marker and antibody information were: mouse monoclonal anti-human neutrophil elastase [clone NP57](Dako, Glostrup, Denmark) for neutrophils, mouse monoclonal anti-human CD68 [clone KP1](Abcam, Cambridge, United Kingdom) for macrophages, mouse monoclonal anti-human Mast cell tryptase [clone AA1](Abcam, Cambridge, United Kingdom) for mast cells, mouse monoclonal anti-human CD4 [clone 4B12](Dako, Glostrup, Denmark) for helper T cells, mouse monoclonal anti-human CD8 [clone C8/144B](Thermo Scientific, Fremont, CA) for cytotoxic T cells, and mouse monoclonal anti-human Foxp3 [clone,236A/E7](Abcam, Cambridge, United Kingdom) for regulatory $T$ cells. Tissues were embedded in paraffin and sectioned at $4 \mathrm{~mm}$ with a Leica microtome (Leica, Wetzlar, Germany).

For immunohistochemistry, the cellular markers were stained by using a modified horseradish peroxidase (HRP) technique with the DakoCytomation EnVision + System-HRP (Dako). Sections were preheated with Target Retrieval Buffer (Dako) and were incubated with the primary antibodies at respective optimized dilution at $4^{\circ} \mathrm{C}$ overnight. Then the slides were incubated with Dako EnVision+System-HRP (Dako) at room temperature for 30 minutes. Diaminobenzidine was used as a substrate for color development. All slides were counterstained with hematoxylin.

RNA extraction and quantitative real-time PCR

Total RNA was extracted from frozen ACP, BNP and health control tissues in RNAlater using the mirVanaTM isolation kit (Applied Biosystems). $1 \mu \mathrm{g}$ of total RNA was reverse transcribed with the TaqMan Reverse Transcription Reagents Kit (Applied Biosystems) according to the manufacturer's protocol. The expression level of FOXP3 was evaluated by using SYBR Green gene expression assays (Promega, Madison, WI, USA). Relative gene expression was calculated using the comparative $2-{ }^{\Delta \Delta} \mathrm{Ct}$ method with the housekeeping gene (glyceraldehyde-3-phosphate dehydrogenase, GAPDH). FOXP3 and GAPDH amplification were performed with following primers: FOXP3 forward (5'-ACATTCCCAGAGTTCCTC-3'), FOXP3 reverse (5'-AGATCTCATTGAGTGTCCG-3'). GAPDH forward (5'-ACAGTTGCCATGTAGACC-3'), and GAPDH reverse (5'- TTTTTGGTTGAGCACAGG-3').

\section{Evaluation of epithelium patterns}

With regards to the evaluation of epithelial hyperplasia, an arbitrary scoring system was developed: score 1, normal epithelium (pseudostratified ciliated columnar epithelium) or no obvious hyperplastic epithelial structure (the layer of epithelial cells is $\leq 4)$; score 2, mild epithelial hyperplasia (the layer of epithelial cells is $>4$ but $\leq 8$ ); score 3 , moderate epithelial hyperplasia (the layer of epithelial cells is $>8$ but $\leq 16$ ); score 4 , severe epithelial hyperplasia (the layer of epithelial cells is $>16$ ).

Goblet cell hyperplasia was defined as the presence of 2 or more layers of goblet cells in the epithelium.

Squamous metaplasia was identified in specimens where the epithelium lacked the pseudostratified columnar epithelial structure and associated with the absence of goblet cells and cilia concurrently (these cells were replaced by squamous epithelium). 
Table 1. Demographics and clinical characteristics of patients.

ACP $(n=33) \quad$ BNP $(n=49) \quad$ Controls $(n=50)$

$\begin{array}{lccc}\begin{array}{l}\text { Gender } \\ \text { (Male/female) }\end{array} & 27 / 6 & 37 / 12 & 43 / 7 \\ \text { Age }^{*} \text { (years) } & 15(9.5-26.5) & 49(38.5-56) & 32(19-47) \\ \text { Atopy }^{\#} & 4(12.1 \%) & 17(34.7 \%) & 9(18.0 \%) \\ \text { Asthma }^{\S} & 2(6.06 \%) & 10(20.4 \%) & 0 \\ \text { Recurrence }^{\text {Smoking }}{ }^{\text {R }} & 9(27.3 \%) & 11(22.4 \%) & \mathrm{NA} \\ & 4(12.1 \%) & 18(36.7 \%) & 8(16.0 \%)\end{array}$

* Age is presented as the median and the 25th-75th percentiles (interquartile range) in parenthesis. " By either positive serum specific immunoglobulin $\mathrm{E}(\mathrm{lg} \mathrm{E})$ test or positive skin prick test to common allergens. ${ }^{\S}$ By self-reported physician-diagnosed asthma. " History of cigarette smoking up to 4 weeks before surgery. $\mathrm{ACP}=$ antrochoanal polyps; BNP $=$ bilateral nasal polyps; NA = not applicable.

\section{Evaluation of inflammatory cell patterns}

For each sample, the highest densities of inflammatory cell infiltration, as assessed by low-power microscopic examination, were chosen for high-power examination. Three high-power field (HPFs) (400×magnification) and at least 300 leukocytes were examined under the microscope. Structural cells including epithelial cells, fibroblasts, glandular cells, and endothelial cells were not counted. The proportion of each type of cell in the three HPFs with respect to the total number of inflammatory cells were calculated using the following formula: Proportion of type of cell $=(n 1+n 2+n 3) /(m 1+m 2+m 3) \times 100 \%$, where $n 1, n 2$ and $n 3$ were the numbers of the type of inflammatory cell investigated in question in three HPFs, and $\mathrm{m} 1, \mathrm{~m} 2$ and $\mathrm{m} 3$ were the number of inflammatory cells in these three HPFs. Two researchers independently evaluated each section. Where discrepancies in evaluation arose, a blinded third researcher evaluated the section independently, followed by discussion with both researchers to resolve the discrepancy.

Specimens were categorized as eosinophilic or neutrophilic whereby the proportion of eosinophils or neutrophils, respectively, exceeded $10 \%$ of the total number of inflammatory cells. This cutoff was chosen because the median proportions of these two types of inflammatory cells hovered around $10 \%$ of all inflammatory cells in our preliminary study. This cutoff value was in line with other studies that classified polyps into eosinophilic or neutrophilic polyps, based on which of these two types of cells were found in higher proportions.

\section{Statistical analysis}

All statistical analyses of data were conducted using SPSS statistical software version 22.0 (SPSS Inc., Chicago, IL, USA). Mann-Whitney $U$ test and chi-square test were employed to assess for differences between groups. The Spearman rank ana- lysis was used to assess the correlations between two selected parameters from clinical characteristics, epithelial hyperplasia and inflammatory cells infiltration. Statistical significance was determined by a $\mathrm{p}$-value of less than 0.05 .

\section{Results}

\section{Patient characteristics}

The clinical characteristics are summarized in Table 1. The median age of ACP was 15 years old which was much younger than 49 years old in BNP. Both ACP and BNP were male predominant in this study. In BNP, 34.7\% ( $n=17)$ and $20.4 \%(n=10)$ of cases were associated with atopy and asthma respectively, but only $12.1 \%(n=4)$ and $6.06 \%(n=2)$ of ACP patients were atopic and asthmatic respectively. $27.3 \%$ of ACP cases had a history of recurrence, and in BNP it was $22.4 \%$.

\section{Prevalence of epithelial remodeling}

All three types of epithelial remodeling (epithelial hyperplasia, goblet cell hyperplasia and squamous metaplasia) were found in ACP (Figure 1). According to our epithelial hyperplasia scoring system, $39.4 \%$ of ACP cases were classified as score 2 and were the largest proportion; whereas in BNP, $47.8 \%$ of the cases were score 4 and comprise the largest population. Epithelial hyperplasia in BNP was much more severe than in ACP $(p=0.004)$ although ACP's epithelial hyperplasia was still more severe than the control's ( $p<0.001)$. Goblet cell hyperplasia was common in BNP epithelium and was observed in $78.3 \%$ of BNP cases. However, only $45.5 \%(n=15)$ of ACP cases had goblet cell hyperplasia in their epithelium, which was significantly less frequently seen compared to patients with $\mathrm{BNP}(\mathrm{P}=0.003)$. With regards to squamous metaplasia, no significant difference was found between ACP and BNP (Table 2).

\section{Inflammatory cellular infiltration in two types of nasal polyps}

87.9\% (29 out of 33) of ACP tissues demonstrated neutrophilia, and in BNP, neutrophilic polyps comprise $42.9 \%$ (21 out of 49) of the study population $(p<0.001)$. Meanwhile, only $15.2 \%$ (5 out of 33) of patients with ACP showed tissue eosinophila, which was significantly lower than the $71.4 \%$ (35 out of 49 ) in patients with BNP $(p<0.001)$ (Table 2).

The median percentages of the types of inflammatory cells are described in Table 3. In ACP, the most common infiltrating cells were neutrophils (median of $38.3 \%$ of all inflammatory cells), followed by $\mathrm{CD}^{+} \mathrm{T}$ cells (17.1\%), macrophages (13.8\%), CD4 ${ }^{+} \mathrm{T}$ cells (12.9\%), mast cells (3.6\%) and eosinophils (3\%). The ratio of CD4 ${ }^{+}$ $\mathrm{T}$ cells to $\mathrm{CD} 8^{+} \mathrm{T}$ cells was 0.92 , and Foxp $3^{+} \mathrm{T}$-reg cells positive staining were observed and were 0.76 of all inflammatory cells in ACP. In BNP, the most common infiltrating cells were eosinophils (median of $24.2 \%$ of all inflammatory cells), followed by CD8 ${ }^{+} \mathrm{T}$ cells (16.8\%), macrophages (11.5\%), CD4 ${ }^{+} \mathrm{T}$ cells $(11.4 \%)$, 
A: H\&E staining

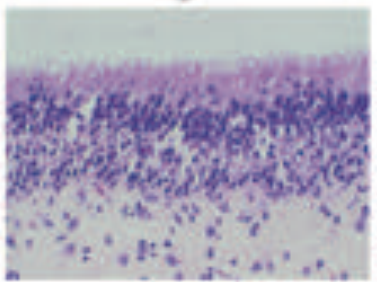

(1) $\mathrm{ACP}$

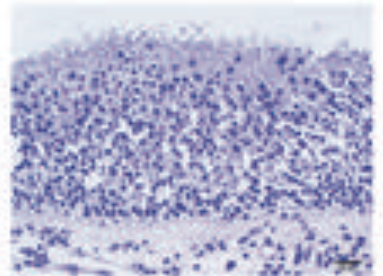

(2) BNP

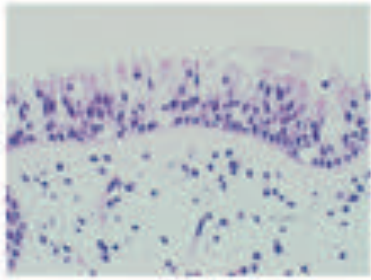

(3) Control

\section{Bi MUC5AC staining for goblet cells}

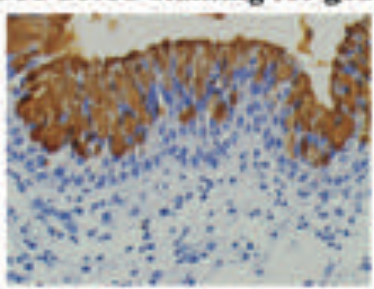

(1) ACP

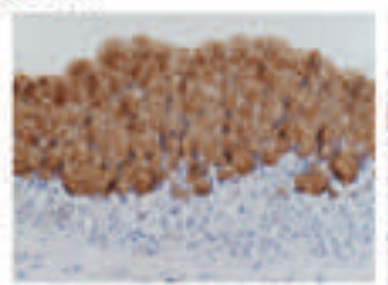

(2) BNP

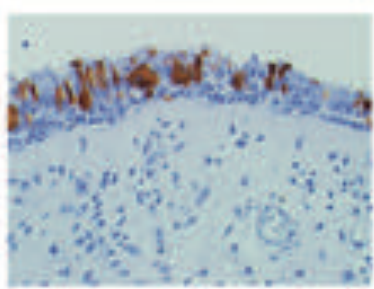

(3) Control

C: IVL staining for squamous cells

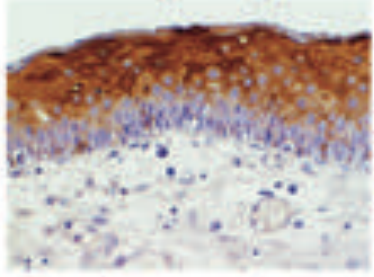

(1) ACP

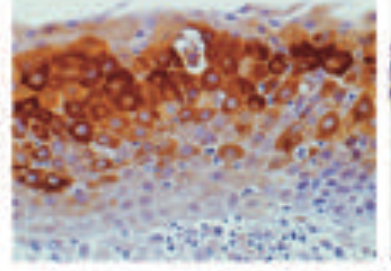

(2) BNP

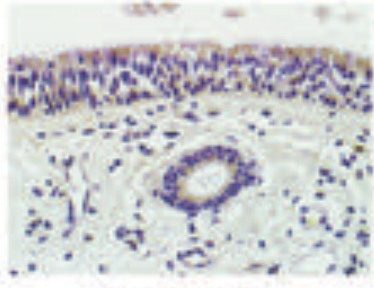

(3) Control

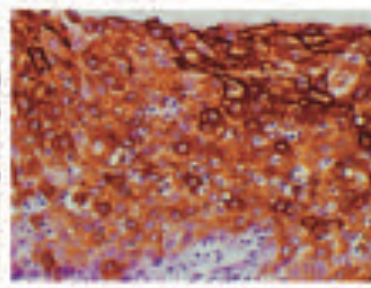

(4) Nasal inverted papilloma

Figure 1. Four types epithelium stained with H\&E staining. All the photos are taken under a light microscope at $\times 400$ magnification. A) (1) Epithelial hyperplasia from ACP, (2) Epithelial hyperplasia from BNP, (3) Non-remodeling epithelium from controls; B) (1) Goblet cell hyperplasia from ACP, (2) Goblet cell hyperplasia from BNP, (3) MUC5AC staining from controls; C) (1) Squamous metaplasia from ACP, (2) Squamous metaplasia from BNP, (3) Involucrin staining from controls, (4) Squamous metaplasia - Involucrin staining from nasal inverted papilloma.

neutrophils (7.7\%) and mast cells (5.3\%). The ratio of $\mathrm{CD} 4^{+} \mathrm{T}$ cells to $C D 8^{+} T$ cells was 0.68 , and Foxp $3^{+} T$-reg cells positive staining were observed (2.06\% of all inflammatory cells) in BNP.

Figures 2 and 3 show typical inflammatory cells infiltration in three types of tissues. The median proportion of neutrophils (38.3\% vs $7.7 \%, 38.3 \%$ vs $1.9 \%$ ) was significantly higher in ACP compared to BNP and controls (both $\mathrm{p}<0.001$ ). The median proportions of macrophages $(13.8 \%$ vs $6.6 \%, p<0.001)$ and $C D 8^{+}$ T cells $(17.1 \%$ vs $13.1 \%, \mathrm{p}<0.01)$ were significantly higher in ACP compared to controls, but no significant differences were found between ACP and BNP. Eosinophil infiltration in ACP was significantly lower compared to BNP ( $3.0 \%$ vs $24.2 \%, p<0.001)$ but still significantly higher than controls $(3.0 \%$ vs $0.34 \%, p<0.001)$. Mast cells and Foxp $3^{+}$T-reg cells infiltration in ACP were significantly lower compared to both BNP ( $3.6 \%$ vs $5.3 \%, p<0.01 ; 0.76 \%$ vs $2.06 \%, \mathrm{p}<0.01)$ and Control ( $3.6 \%$ vs $7.1 \%, \mathrm{p}<0.001 ; 0.76 \%$ vs $1.3 \%, p<0.01)$.

\section{Quantitative PCR evaluation}

FOXP3 showed higher expression levels in BNP than in ACP and control subjects, despite a lack of significant difference $(p=0.31$ and $p=0.19$, respectively; Figure 3 ).

Relationships of clinical characteristics and histopathological features in ACP

In ACP, eosinophil infiltration was found to be positively correlated with the history of asthma $(r=0.378, p=0.026)$. The percentage of macrophage in ACP tissues had a significantly negative correlation with epithelial hyperplasia $(r=-0.503, p=0.003)$ and goblet cell hyperplasia $(r=-0.511, p=0.002)$. The infiltration of $\mathrm{CD} 8{ }^{+} \mathrm{T}$ cell and squamous metaplasia had a positive correlation $(r=0.346, p=0.048)$. No other statistically significant relationships in ACP were found between the types and proportions of inflammatory cells and clinical characteristics or epithelial remodeling listed in Table 1 and Table 2. 
Table 2. Histopathology features in ACP, BNP and controls.

\begin{tabular}{|c|c|c|c|c|c|c|}
\hline & $\begin{array}{c}\text { ACP } \\
(n=33)\end{array}$ & $\begin{array}{c}\text { BNP } \\
(n=49)\end{array}$ & $\begin{array}{l}\text { Controls } \\
(n=50)\end{array}$ & $\begin{array}{c}\text { ACP vs. BNP } \\
\text { P Value }\end{array}$ & $\begin{array}{c}\text { ACP vs. IT } \\
\text { P Value }\end{array}$ & $\begin{array}{c}\text { BNP vs. IT } \\
\text { P Value }\end{array}$ \\
\hline Epithelial hyperplasia *,\# & & & & 0.004 & $<0.001$ & $<0.001$ \\
\hline Score 1 & $4(12.1 \%)$ & $3(6.5 \%)$ & $40(80 \%)$ & & & \\
\hline Score 2 & $13(39.4 \%)$ & $4(8.7 \%)$ & $10(20 \%)$ & & & \\
\hline Score 3 & $8(24.2 \%)$ & $17(37.0 \%)$ & 0 & & & \\
\hline Score 4 & $8(24.2 \%)$ & $22(47.8 \%)$ & 0 & & & \\
\hline Goblet cell hyperplasia ${ }^{\S}$ & 15 (45.5\%) & $36(78.3 \%)$ & $4(8 \%)$ & 0.003 & $<0.001$ & $<0.001$ \\
\hline Squamous metaplasia " & $5(15.2 \%)$ & 9 (19.6\%) & 0 & NS & 0.018 & 0.003 \\
\hline \multicolumn{7}{|l|}{ Eosinophil and neutrophil } \\
\hline Eosinophilia ${ }^{* *}$ & $5(15.2 \%)$ & $35(71.4 \%)$ & $2(4 \%)$ & $<0.001$ & NS & $<0.001$ \\
\hline Neutrophilia \#\# & 29 (87.9\%) & $21(42.9 \%)$ & $3(6 \%)$ & $<0.001$ & $<0.001$ & $<0.001$ \\
\hline
\end{tabular}

* Three bilateral nasal polyps tissue samples with poor epithelial structure were not evaluated. * For the evaluation of epithelial hyperplasia, an arbitrary scoring system was developed: score 1, normal or no obvious hyperplastic epithelial structure (the layer of epithelial cells is $\leq 4$ ); score 2 , mild epithelial hyperplasia (the layer of epithelial cells is $>4$ but $\leq 8$ ); score 3 , moderate epithelial hyperplasia (the layer of epithelial cells is $>8$ but $\leq 16$ ); score 4, severe epithelial hyperplasia (the layer of epithelial cells is $>16$ ). ${ }^{\S}$ Goblet cell hyperplasia was defined as 2 or more layers of goblet cells in the epithelium." Squamous metaplasia was identified in specimens where the epithelium had lost its pseudostratified columnar epithelial structure with absence of goblet cells and cilia and was replaced by squamous epithelium. ${ }^{* *}$ Infiltration of eosinophils in nasal tissues was categorized as eosinophilia when the percentage of eosinophils exceeded 10\%. ${ }^{\#}$ Infiltration of neutrophils in nasal tissues was categorized as neutrophilia when the percentage of neutrophils exceeded 10\%. ACP = antrochoanal polyps; BNP = bilateral nasal polyps; NS = not significant.

Table 3. Immunopathological features of ACP, BNP and controls.

\begin{tabular}{|c|c|c|c|c|c|c|}
\hline $\begin{array}{l}\text { Inflammatory or im- } \\
\text { mune cell percentage } \\
\text { or ratio * }\end{array}$ & $\begin{array}{c}\text { ACP } \\
(n=33)\end{array}$ & $\begin{array}{c}\text { BNP } \\
(n=49)\end{array}$ & $\begin{array}{l}\text { Controls } \\
(n=50)\end{array}$ & $\begin{array}{l}\text { ACP vs. BNP } \\
\text { P Value }\end{array}$ & $\begin{array}{l}\text { ACP vs. IT } \\
\text { P Value }\end{array}$ & $\begin{array}{c}\text { BNP vs. IT } \\
\text { P Value }\end{array}$ \\
\hline Eosinophil & $3.0(0.83,7.7)$ & $24.2(7.5,45.3)$ & $0.34(0.0,1.9)$ & $<0.001$ & $<0.001$ & $<0.001$ \\
\hline Neutrophil & $38.3(17.5,58.0)$ & $7.7(3.2,22.1)$ & $1.9(0.72,4.1)$ & $<0.001$ & $<0.001$ & $<0.001$ \\
\hline Macrophage & $13.8(8.2,19.0)$ & $11.5(7.4,15.0)$ & $6.6(4.4,7.7)$ & NS & $<0.001$ & $<0.001$ \\
\hline Mast cell & $3.6(2.7,6.0)$ & $5.3(3.8,8.3)$ & $7.1(5.6,10.7)$ & $<0.01$ & $<0.001$ & NS \\
\hline $\mathrm{CD}^{+} \mathrm{T}$ cell & $12.9(10.0,17.9)$ & $11.4(8.0,14.4)$ & $16.5(11.9,20.0)$ & NS & NS & $<0.001$ \\
\hline $\mathrm{CD}^{+} \mathrm{T}$ cell & $17.1(11.1,22.7)$ & $16.8(12.4,24.0)$ & $13.1(9.9,15.5)$ & NS & $<0.01$ & $<0.001$ \\
\hline $\mathrm{CD}^{+} / \mathrm{CD}^{+}$ratio & $0.92(0.54,1.10)$ & $0.68(0.54,0.84)$ & $1.11(1.03,1.46)$ & $<0.01$ & $<0.001$ & $<0.001$ \\
\hline Regulator T cell (Foxp3+) & $0.76(0.43,1.25)$ & $2.06(0.38,3.38)$ & $1.3(0.75,2.1)$ & $<0.01$ & $<0.01$ & NS \\
\hline
\end{tabular}

* Percentages and ratios are presented as the median and the 25th-75th percentiles (interquartile range) in parenthesis. ACP = antrochoanal polyps; BNP = bilateral nasal polyps; NS = not significant.

\section{Discussion}

In this study, we conducted a comprehensive microscopic examination of ACP from Northern China, and established several important clinical and histological features and their associations. We also compared these parameters in ACP with BNP and Control. We recognize that Control tissues should be ideally taken from the maxillary antrum (postulated origin of ACP). Unfortunately this is ethically unsound in patients with non- diseased sinuses, hence biopsies of inferior turbinate mucosa were obtained as controls. A moderate epithelial hyperplasia (score 2) was the most common forms of epithelial change in the ACPs. A variety of inflammatory cell types were infiltrated in the ACP mucosa, with neutrophils being the dominant inflammatory cell type.

It is known that ACPs most commonly occur in children and young adults ${ }^{(1)}$. Recently, a study from South Korea found that 

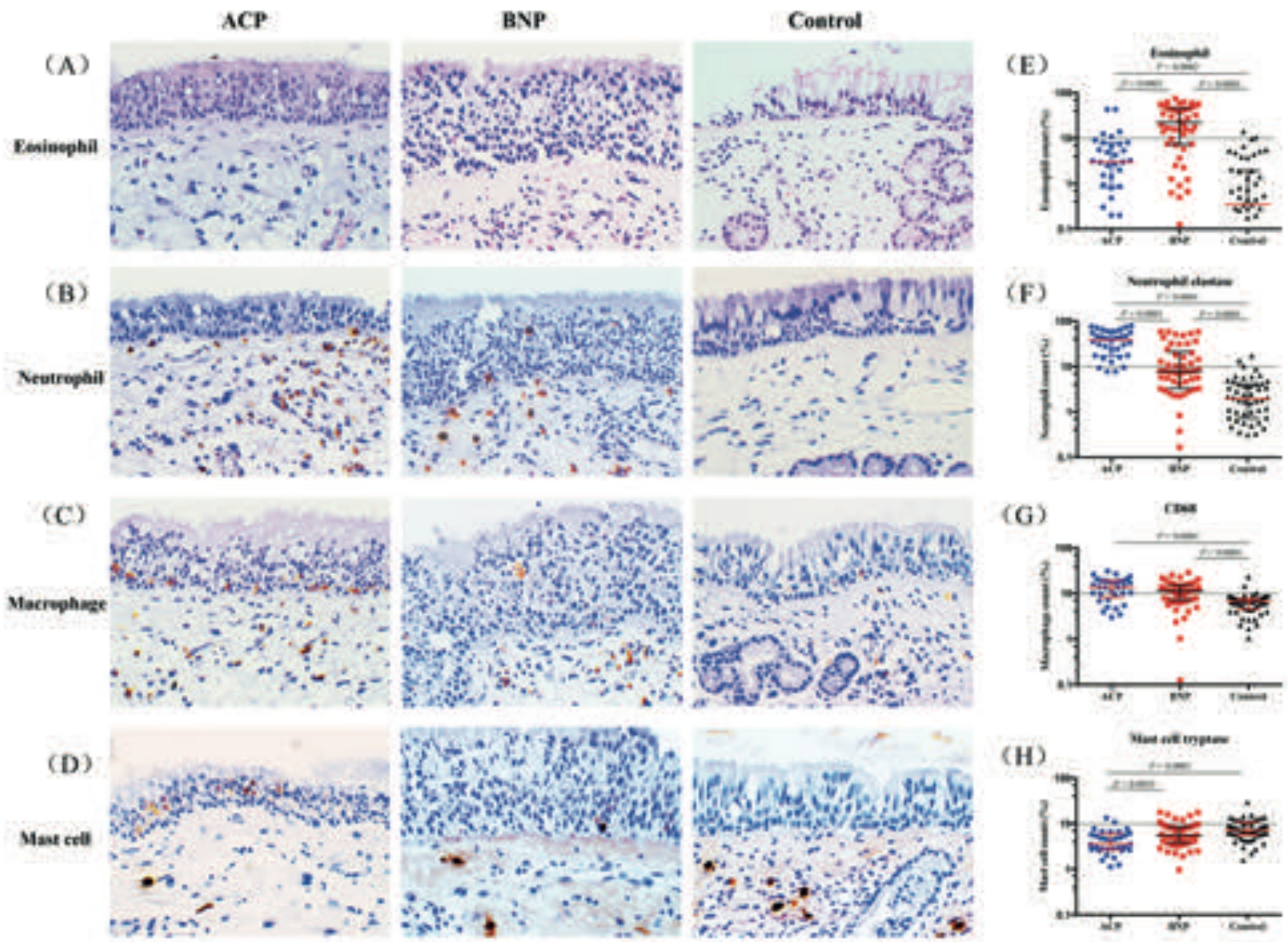

(H)

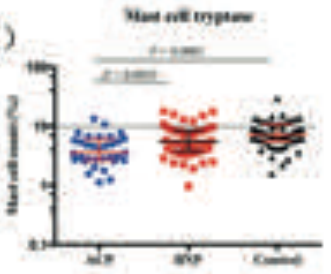

Figure 2. Infiltration and distribution of eosinophils (A), neutrophils (B), macrophages (C) and mast cells (D) in antrochoanal polyps (ACPs), bilateral nasal polyps (BNPs) and controls. Original magnification $400 \times($ scale bar $=50 \mu \mathrm{m}$ ). Comparisons of inflammatory cell counts between groups were made by Mann-Whiney two-tailed test $(\mathrm{E}-\mathrm{H})$. Scatter dot plots were shown with median and interquartile range values.

approximately $40 \%$ of their ACP cases were between 30 and 65 years ${ }^{(5)}$, and claimed that ACPs may manifest at any age. In our study, although the median age of 33 ACP patients was 15 years old, we do have 12 ACP cases older than 18 ranging from 22 to 39 years old, and one patient as old as 79. Therefore, the findings in our study were consistent with previous reports ${ }^{1,5,15-}$ 17). Several previous studies reported a male predominance in ACP ${ }^{(5,15-17)}$, and our data confirmed this characteristic in Chinese ACP cases. Allergic background of ACP patients was reported in some cases but no association was found between them ${ }^{(18,19)}$. We have identified 4 allergic ACP cases in our study, but no statistical significant correlations were found between allergy and histological features, therefore it seems that in these 4 cases, the allergic process may be coincident with the polyps but did not significantly contribute to their pathogenesis. However, asthma background in our study was found to be positively correlated with eosinophil infiltration in mucosa, which might imply that asthma does not significantly contribute to the pathogenesis of ACP because of the low infiltration of eosinophils in most mucosa of ACP. The generally accepted treatment of ACPs is endoscopic surgical removal because of its shorter recovery time and relatively few side effects ${ }^{(3)}$. Recurrence of ACPs is often postulated to be due to the regrowth of any missed residual polypoid lesions within the maxillary sinus ${ }^{(20)}$. In this study, the recurrence rate of ACPs was $27.3 \%$, but because the previous surgeries of the recurrent patients were not performed in our hospital, details and circumstances of the previous operations cannot be found and verified. However, no statistical significant relationships were found between recurrence and the types and proportions of inflammatory cells or epithelial remodeling in ACPs. This is in contrast to eosinophilic infiltration in mucosa, which was found to predict nasal polyp recurrence in BNP (21). This may imply a very different inflammatory pathogenesis between ACP and BNP.

Epithelial hyperplasia involves excessive proliferation of basal cells inclining towards cellular renewal, at the expense of differentiation. This leads to an imbalance of ciliated and secretory cells and may affect mucociliary clearance and other functions 


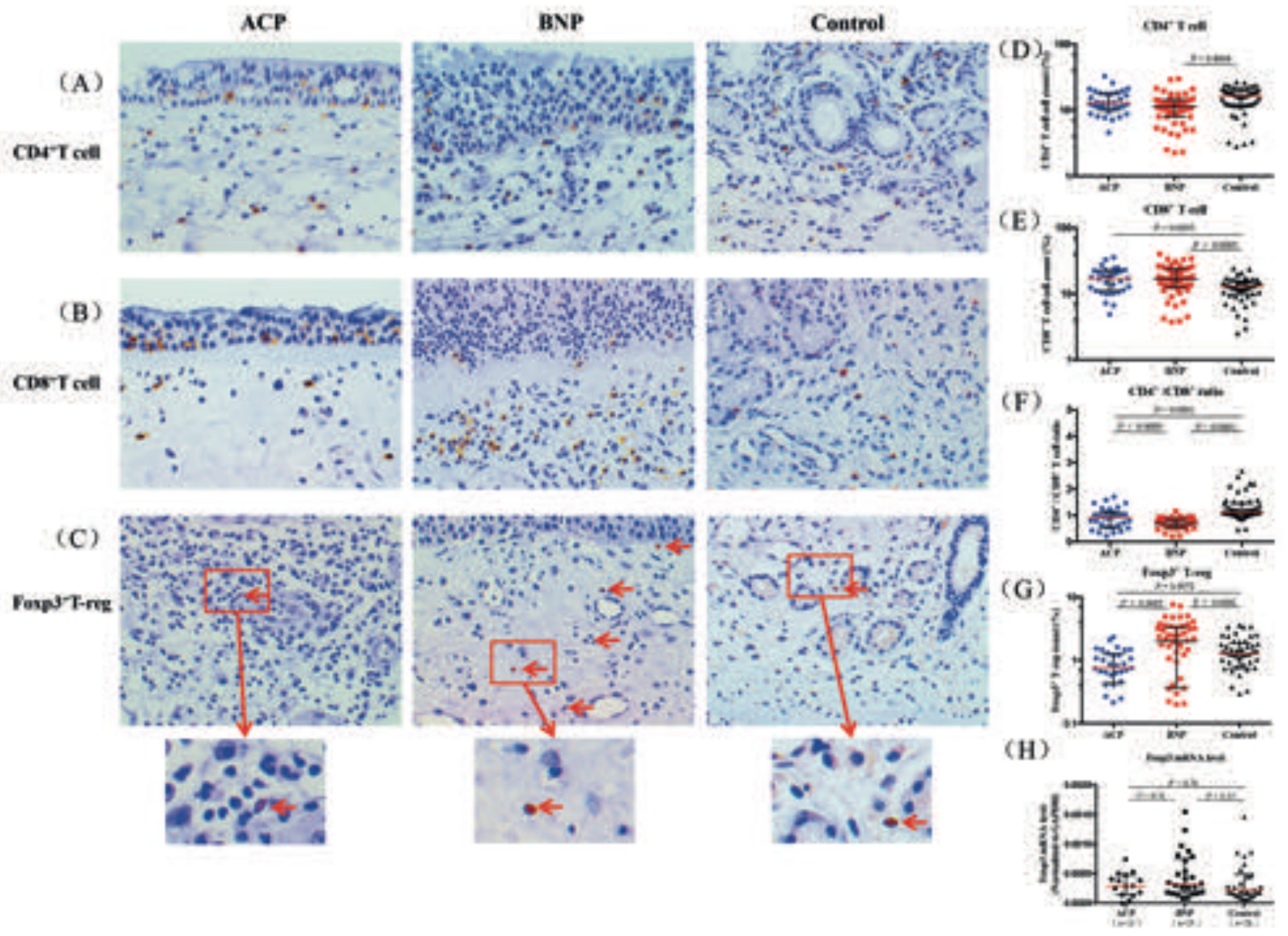

Fig. 3. Infiltration and distribution of T cell subsets including CD4+ T cells (A), CD8+T cells (B) and FoxP3+T-reg cells(C) in antrochoanal polyps (ACPs), bilateral nasal polyps (BNPs) and controls. Original magnification $400 \times($ scale bar $=50 \mu \mathrm{m}$ ). Comparisons of inflammatory cell counts be among groups were made by Mann-Whiney two-tailed test (D-G). Scatter dot plots were shown with median and interquartile range values.

of nasal mucosa ${ }^{(22)}$. Epithelial hyperplasia and goblet cell hyperplasia are typical histopathological features of nasal polyps ${ }^{(11,23)}$. In this study, ACPs showed less severe epithelial hyperplasia and goblet cell hyperplasia compared to BNPs, and interestingly, the increased infiltration of macrophages in ACP mucosa had a significantly negative correlation with epithelial hyperplasia $(r$ $=-0.503, p=0.003)$ and goblet cell hyperplasia $(r=-0.511, p=$ 0.002 ). As macrophage polarization is increasingly recognized as an important pathogenetic factor in inflammatory and neoplastic diseases ${ }^{(24)}$, macrophages in ACP might play a protective role in its pathogenesis. Squamous metaplasia represents a particularly severe form of nasal epithelial remodeling as there was a complete loss of cilia and goblet cells, and the associated loss of the fundamental features of nasal epithelium: mucus production and ciliary clearance ${ }^{(11)}$. An association was established in this study that the infiltration of $C D 8^{+} \mathrm{T}$ cell was positively associated with squamous metaplasia in ACP that might promote the understanding of the pathophysiologic significance of epithelial remodeling in antrochoanal polyps.
Research in CRS showed that eosinophilic CRS could be associated with steroid responsiveness; whereas neutrophilic polyps are less sensitive to glucocorticosteroids $(\mathrm{GCSs}){ }^{(14)}$. Mucosal eosinophilia may help predict recurrence of nasal polyp ${ }^{(21)}$. All these data serve to remind us that immunopathological studies in ACP is important and necessary. Tissue eosinophilia and neutrophilia in nasal polyps, especially BNP exhibits significant geographic and ethnic differences: pronounced eosinophilic infiltration is predominant in Western white patients, whereas bilateral nasal polyps in East Asia presents with more mucosal neutrophilia (21). A study ${ }^{(25)}$ of 8 ACP patients from Europe showed low eosinophils and high neutrophils infiltration in mucosa, which is in line with eosinophils and neutrophils infiltration patterns in our study. Currently, no different patterns of mucosa eosinophilia and neutrophilia were found to be associated with geographic and ethnic differences.

Recently, a subset of mast cells was reported to found in bilateral nasal polyps' glandular epithelial cells that produced tryptase, carboxypeptidase A3, and chymase ${ }^{(26)}$. Because chy- 
mase is a known inducer of mucus, it is hypothesized that these specialized mast cells may play a role in the overproduction of mucus commonly seen in bilateral nasal polyps ${ }^{(26)}$. We found a lower rate of goblet cell hyperplasia and less infiltration of mast cells in ACP compared to BNP, but no significant correlation was found between mast cells infiltration and goblet cell hyperplasia in ACP. Therefore, the causal relationship between the two in ACP needs to be explored and dissected further. Studies on regulatory $\mathrm{T}$ (Treg) cells are arising in recent years, but the role of Treg cells in CRS is still controversial ${ }^{(8)}$. Some studies showed that Treg cells were impaired in CRSwNP, thus leading to an imbalance in pro-inflammatory and anti-inflammatory responses ${ }^{(27,28)}$. But some studies reported increased number of Treg cells in nasal polyps ${ }^{(13,29)}$.

For the first time, our study reported decreased Treg cells infiltration in antrochoanal polyps compared to nasal polyps and inferior turbinate mucosa from controls. And bilateral nasal polyps in our study revealed an elevated number of Treg cells. It is likely due to the fact that there is very low number of FOXP3 producing cells in the lamina propria of polyp tissue with low detectable mRNA expression levels of FOXP3, therefore the results of qPCR might not be parallel to those of immunohistochemical staining. However, further studies examining Treg cells are needed to elucidate their role and whether they are importan in the pathology of ACP and CRS.

\section{Conclusion}

The antrochoanal polyp (ACP) is likely associated with none type 2-driven inflammation with increased infiltration of neutrophils, macrophages and $\mathrm{CD} 8^{+} \mathrm{T}$ cells and decreased FOXP3 ${ }^{+} \mathrm{T}$-reg cells, which reflect the activity of cell-mediated innate immune response. Less severe epithelial hyperplasia and goblet cell hyperplasia compared to bilateral nasal polyps (BNP) might explain the relative mild clinical symptoms in ACP. ACP and BNP may differ in their pathogenesis.

\section{Acknowledgement}

This study was supported by grants from the National Medical Research Council (NMRC/CIRG/1458/2016), Singapore, the Major Research Development Program of Shandong Province (Grant awarded number 2016GSF201084) and the National Nature Science Foundation of China (Grant awarded number 81670909).

\section{Authorship contribution}

Conceived and designed the experiments: DW, HZ. Collected the samples: PJ, XZi, LS, HZ. Performed the experiments: PJ, XZ. Analyzed the data:TCC, PJ, LS. Contributed reagents/materials/ analysis tools: JL, YY, TCC. Wrote the paper: PJ, TCC, DW.

\section{Conflict of interest}

The authors declared that no conflict of interest exists.

\section{References}

1. Maldonado M, Martinez A, Alobid I, Mullol J. The antrochoanal polyp. Rhinology 2004; 42:178-182

2. Hirshoren N, Neuman T, Gross M, Eliashar R. Angiogenesis in chronic rhinosinusitis with nasal polyps and in antrochoanal polyps. Inflamm Res 2011; 60:321-327.

3. Yaman H, Yilmaz S, Karali E, Guclu E, Ozturk O. Evaluation and management of antrochoanal polyps. Clin Exp Otorhinolaryngol 2010; 3:110-114.

4. Sabino HAC, Faria FM, Tamashiro E, et al. Bilateral antrochoanal polyp: case report. $\mathrm{Br}$ J Otorhinolaryngol 2014; 80:182-183.

5. Lee DH, Yoon TM, Lee JK, Lim SC. Difference of antrochoanal polyp between children and adults. Int J Pediatr Otorhinolaryngol 2016; 84:143-146

6. Fokkens WJ, Lund VJ, Mullol J, et al. EPOS 2012: European position paper on rhinosinusitis and nasal polyps 2012. A summary for otorhinolaryngologists. Rhinology 2012; 50:1-12.

7. Pawankar R, Nonaka M. Inflammatory mechanisms and remodeling in chronic rhinosinusitis and nasal polyps. Curr Allergy Asthma Rep 2007; 7:202-208.

8. Stevens WW, Lee RJ, Schleimer RP, Cohen NA. Chronic rhinosinusitis pathogenesis. Allergy Clin Immunol 2015; 136:1442-1453.

9. Rock JR, Randell SH, Hogan BL. Airway basa stem cells: a perspective on their roles in epithelial homeostasis and remodeling. Dis Model Mech 2010; 3:545-556.

10. Randell SH. Airway epithelial stem cells and the pathophysiology of chronic obstructive pulmonary disease. Proc Am Thorac Soc 2006; 3:718-725.

11. Gao T, Ng CL, Li C, et al. Smoking is an independent association of squamous metaplasia in Chinese nasal polyps. Int Forum Allergy Rhinol 2016; 6:66-74.

12. Zhao L, Li CW, Jin P, et al. Histopathological features of sinonasal inverted papillomas in chinese patients. Laryngoscope 2016 126:E141-147.

13. Li CW, Zhang KK, Li TY, et al. Expression profiles of regulatory and helper T-cellassociated genes in nasal polyposis. Allergy 2012; 67:732-740

14. Wen W, Liu W, Zhang L, et al. Increased neutrophilia in nasal polyps reduces the response to oral corticosteroid therapy. J Allergy Clin Immunol 2012; 129:1522-1528 e1525.

15. Nikakhlagh S, Rahim F, Saki N, Mohammadi $\mathrm{H}$, Maliheh YM. Antrochoanal polyps: report of 94 cases and review the literature. Niger J Med 2012; 21:156-159.

16. Yuca K, Bayram I, Kiroglu AF, et al. Evaluation and treatment of antrochoanal polyps. J Otolaryngol 2006; 35:420-423.

17. Sayed RH, Abu-Dief EE. Does antrochoanal polyp present with epistaxis? J Laryngol Otol 2010; 124:505-509.

18. Składzień J1, Litwin JA, NowogrodzkaZagorska M, Wierzchowski W. Morphological and clinical characteristics of antrochoanal polyps- comparison with chronic inflammation-associated polyps of the maxillary sinus. Auris Nasus Larynx 2001 Apr;28(2):137-41.

19. Aktas D, Yetiser S, Gerek M, Kurnaz A, Can C, Kahramanyol M. Antrochoanal polyps: analysis of 16 cases. Rhinology 1998; 36:81-85.

20. Endoscopic management of paediatric antrochoanal polyp: our experience.

21. Bachert C, Zhang L, Gevaert P. Current and future treatment options for adult chronic rhinosinusitis: Focus on nasal polyposis. J Allergy Clin Immunol 2015; 136:1431-1440; quiz 1441.

22. Li YY, Li CW, Chao SS, et al. Impairment of cilia architecture and ciliogenesis in hyperplastic nasal epithelium from nasal polyps. J Allergy Clin Immunol 2014; 134:1282-1292.

23. Yu XM, Li CW, Li YY, et al. Down-regulation of EMP1 is associated with epithelial hyperplasia and metaplasia in nasal polyps. Histopathology 2013; 63:686-695.

24. Barros MH, Hauck F, Dreyer JH, Kempkes B, Niedobitek G. Macrophage polarisation: an immunohistochemical approach for identifying M1 and M2 macrophages. PLoS One 2013; 8:e80908. 
25. Ebbens FA, Toppila-Salmi SK, Renkonen JA et al. Endothelial L-selectin ligand expression in nasal polyps. Allergy 2010; 65:95-102.

26. Takabayashi T, Kato A, Peters ATet al Glandular mast cells with distinct phenotype are highly elevated in chronic rhinosinusitis with nasal polyps. J Allergy Clin Immunol 2012; 130:410-420 e415.

27. Van Bruaene N, Perez-Novo CA, Basinski TM, et al. T-cell regulation in chronic paranasa sinus disease. J Allergy Clin Immunol 2008; 121:1435-1441, 1441 e1431-1433.

28. Lan F, Zhang N, Zhang J, et al. Forkhead box protein 3 in human nasal polyp regulatory $T$ cells is regulated by the protein suppressor of cytokine signaling 3. J Allergy Clin Immunol 2013; 132:1314-1321.

29. Pant $H$, Hughes $A$, Schembri M, Miljkovic $D$, Krumbiegel D. CD4(+) and CD8(+) regulatory $T$ cells in chronic rhinosinusitis mucosa. Am J Rhinol Allergy 2014; 28:e83-89.

\section{Corresponding author 1 :}

De Yun Wang, MD, PhD

Department of Otolaryngology

Yong Loo Lin School of Medicine National University of Singapore

1 Eent Ridge Road

Singapore 119228

Tel: +6567725373

Fax: +6567753820

E-mail: entwdy@nus.edu.sg
Corresponding author 2:

Hai Ling Zhang, PhD

Department of Otolaryngology

The Second Affiliated Hospital,

Shandong University

247 Beiyuan Avenue Jinan,

Shandong 250033

\section{P. R. China}

Tel: +8653185875317

Fax: +8653188962544

E-mail: 15853138360@163.com 